\title{
DE HABERLO SABIDO...: CONDICIONALES CON DE Y PARA
}

\author{
DE HABERLO SABIDO...: \\ CONDITIONAL CLAUSES WITH \\ DE AND PARA
}


En el español, son varias las preposiciones que combinadas con infinitivo o con cláusulas con que, conforman prótasis condicionales. Así, se ha destacado que para las lenguas románicas, por ejemplo, es común que $a$ permita introducir condicionantes; aunque en el caso del español, es el infinitivo preposicional con de la forma más difundida en la actualidad para la expresión de la condicionalidad. Con para, con y sin pueden también constituirse prótasis condicionales; no obstante, estos nexos devenidos en conjunciones más o menos gramaticalizadas no son intercambiables en todos los casos. De hecho, con respecto a de y para, advertimos restricciones de conmutación de una por otra: De (/*Para) llegar temprano, podremos realizar todo lo que tenemos previsto, Para $\left(/{ }^{*} \mathrm{De}\right)$ haber escrito una carta tan linda, debes de ser una niña muy inteligente. Asimismo, si se admite sustitución, se produce una interpretación distinta: Para ser reelegido en un lugar como este (=si querés ser reelegido), tenés que gobernar bien /De ser reelegido en un lugar como este (=si sos / fueras reelegido en un lugar como este), tenés que gobernar bien. Efectivamente, el contraste semántico en estos dos últimos ejemplos se vincula con la interpretación temporal del infinitivo en la prótasis: con para, de posterioridad al condicionado, y con de, de anterioridad.

Palabras Clave: condicionalidad, infinitivos preposicionales, de, para, modalidad

There are several prepositions in Spanish which, if combined with an infinitive or with que clauses, form conditional protases. In this sense, the prepositional infinitive with de is nowadays the most widely used form to express conditionality (although it has been highlighted that in Romance languages, for example, conditions are usually introduced with $a$ ). Furthermore, conditional protases may be formed with para, con and sin; however, these connectives, which have become more or less grammaticalized conjunctions, are not interchangeable in all cases. In the cases of $d e$ and para, in fact, switching is restricted: De (/*Para) llegar temprano, podremos realizar todo lo que tenemos previsto, Para $\left(/{ }^{*} \mathrm{De}\right)$ haber escrito una carta tan linda, debes de ser una niña muy inteligente. Also, in other cases, when substitution is admitted, the sentence is interpreted differently: Para ser reelegido en un lugar como este (=if you want to be re-elected), tenés que gobernar bien /De ser reelegido en un lugar como este (=if you were re-elected in a place like this one), tenés que gobernar bien. Indeed, the semantic contrast is derived, to a large extent, from the temporal interpretation of the infinitive included in the protasis: para denotes posteriority in relation to the condition, whereas de denotes the opposite. This factor (together with others associated with structure conventionalization) is crucial to account for the peculiarities of the expression of conditionality with de and para.

KEY WORDS: conditionality, prepositional infinitives, de, para, modality

RECEPCIÓN: 26/06/2015

ACEPTACión: 9/09/2015 


\title{
DE HABERLO SABIDO...: CONDICIONALES CON DE Y PARA
}

\section{DE HABERLO SABIDO...: CONDITIONAL CLAUSES WITH $D E$ AND PARA}

\begin{abstract}
Ana María Marcovecchio Universidad Católica Argentina /Universidad de Buenos Aires Ana María Judith Pacagnini Universidad Nacional de Río Negro, Sede Andina Andrés Kaller Universidad de Buenos Aires
\end{abstract}

\section{Introducción}

En este trabajo, enmarcado en un enfoque cognitivofuncional, ${ }^{1}$ procuramos ahondar el análisis ya iniciado de los infinitivos adverbiales con de y para que se interpretan como prótasis condicionales. En estos empleos, las preposiciones, si bien exponen un proceso de gramaticalización que las asemeja a conjunciones, mantienen ciertas restricciones en la sustitución de una por otra. Es decir, no se

\footnotetext{
${ }^{1}$ Trabajo realizado en el marco del Proyecto de Reconocimiento Institucional de Equipos de Investigación de la Facultad de Filosofía y Letras de la Universidad de Buenos Aires (PRIG): Las construcciones de preposición + infinitivo de comportamiento adverbial (temporal, causal, de modo, final, abesivo, condicional, concesivo): Los vínculos entre perífrasis verbales, complementos de régimen y cláusulas subordinadas, dirigido por la doctora Ana Marcovecchio y codirigido por la doctora Ana Pacagnini.
} 
decoloran plenamente, sino que revelan la pervivencia de sus significados locativos primarios: 'origen', por un lado, y 'destino' / 'finalidad', por otro, lo que moldea, por así decir, las trayectorias semántico-pragmáticas en que ingresan.

En $\$ 47.1 .2 \mathrm{a}$, la Nueva gramática de la lengua española indica que las subordinadas condicionales y concesivas se han clasificado entre las adverbiales impropias, por sus rasgos negativos: no se sustituyen por adverbios ni aceptan el foco interrogativo. Además, establecen relaciones próximas a las conexiones lógicas o argumentativas. No obstante, dado nuestro planteamiento gradualista según el cual una determinada estructura puede funcionar tanto intrapredicativamente como en posiciones periféricas y dado que los adverbios en -mente también revelan la ductilidad de comportarse no solo como circunstanciales sino también en funciones no dependientes de los verbos, no adoptamos la perspectiva de diferenciar adverbiales propias de impropias.

En relación con los infinitivos preposicionales de lectura adverbial, Vanderschueren (2012) advierte que se utilizan típicamente en contextos no asertivos: desde una perspectiva funcional-cognitiva, la autora sostiene que el infinitivo, en tanto dependiente sintácticamente de otro verbo conjugado, describe un evento que se construye a la luz de otro, el de la predicación principal. Este, al perfilar la evolución temporal, es el que permite también recuperar información gramatical pertinente para la interpretación de la cláusula de infinitivo: específicamente la persona y el tiempo. De ahí que el infinitivo se utilice, por ejemplo, en construcciones de carácter adverbial, en contextos irreales o virtuales, para indicar un evento presupuesto o su- 
bordinado, de trasfondo; es decir, un evento que funciona como el marco interpretativo que ofrece la adverbial a la principal. Se trata de cláusulas semántica y sintácticamente desvinculadas (por lo general, antepuestas y periféricas de enunciación), que tienen una función en la organización y presentación del discurso.

En particular, con respecto a las construcciones condicionales con de, Krnetić (2012) destaca que pueden ser de lectura real, potencial y contrafáctica. Para la autora, las propiedades sobresalientes de este tipo de cláusulas son:

i) una mayor incertidumbre que la expresada por la prótasis con $s i$ (en consonancia con Montolío, 1999 y Hernanz, 1999), y la consiguiente restricción semántica que impide su empleo cuando este contenido no está disponible;

ii) la posición absoluta, marcada por los rasgos prosódicos (la pausa intermedia y el cambio de la entonación); funciona como indicio de que su lectura no puede ser la de un sintagma preposicional strictum sensum, sino la de una cláusula no finita interdependiente con otra.

Asimismo, Marcovecchio, Albano y Kaller (2014) muestran correspondencias, en diferentes lenguas románicas, entre de y si como conjunciones. Si puede introducir, por una parte, preguntas totales, interpretables en ciertos contextos situacionales como exhortaciones, y por otra, situaciones hipotéticas dentro de un período condicional. También la construcción $<d e+$ infinitivo $>$, con el concurso de una serie de propiedades gramaticales y situacionales, está habilitada para transmitir una exhortación, en el empleo argentino por 
lo menos: Yo diría de esperar / [...] mi productor, Andrés Vicente Gómez, me habló de hacer una serie sobre cuentos de Borges, o un contenido condicional hipotético: [...] de presentarse la ocasión, los pampas atacaban a las galeras con sus pasajeros, o las postas del camino o los ranchos de la frontera. ${ }^{2}$ Por consiguiente, se sugiere la existencia de un vínculo entre la lectura condicional de de + infinitivo y las subordinadas sustantivas dependientes de verbos de 'influencia'.

En lo que concierne específicamente a para + infinitivo con interpretación condicional, Marcovecchio y Pacagnini (2013: 108-109), consideran que

El esquema sintáctico constituido por la cláusula con para y la predicación en que se inserta se vuelve un mecanismo apto para activar lecturas que terminan expresando i. una correspondencia de suficiencia entre contenidos, ii. la base inferencial considerada por el locutor para deducir la satisfacción de unas determinadas condiciones o iii. el contenido evidencial que, pese a su factualidad, resulta inoperante sobre la certeza del locutor. En los primeros dos casos, los aquí llamados de suficiencia (1) y procondicionales (2), el contenido expresado en las cláusulas con para sustenta la aserción (sin restricciones o atenuada) del locutor, expresada en la matriz, dado que los constituyentes oracionales convergen en una misma orientación argumentativa, a partir de la noción de alcanzar un parámetro de medida necesaria para lograr un efecto o de la deducción de una causa suficiente:

\footnotetext{
${ }^{2}$ Ejemplos tomados de Marcovecchio, Albano y Kaller (2014: 217, 220, 223). En las sustantivas dependientes de un verbo de 'comunicación' con interpretación de 'influencia', se trata de un caso de variación en el complementizador: de, probablemente, exprese la 'distancia', la asimetría entre el que emite el pedido, la sugerencia o la invitación, y aquel a quien se dirige esa propuesta.
} 
(1) El rompehielos Almirante Irízar tuvo un incendio en 2007 y aún se sigue reparando. Pese a las promesas, nadie sabe cuándo volverá a navegar. Con lo que se ha gastado en su reparación y en el alquiler de una nave rusa para las campañas antárticas, sobra para haber adquirido y superequipado a una embarcación nueva (La Nación, Buenos Aires, 16/12/2012). [Consulta realizada en www.lanacion.com.ar_el 01/03/2014]

(2) Para ser reelegido en un lugar como éste, tenés que gobernar bien. ${ }^{3}$

Llegados a este punto, entonces, nos proponemos, mediante el análisis de un cuerpo de datos tomados de publicaciones periodísticas argentinas en línea, entre 2010 y 2015, explicitar las propiedades típicas que distinguen a las prótasis condicionales de infinitivo con de y para, a partir de la idea de que ambas retienen algo de su caudal significativo asociado a la expresión de la localización espacial y temporal y, por consiguiente, lo proyectan sobre las predicaciones de infinitivo, de manera crucial, en la interpretación de la temporalidad.

\section{De + infinitivo: origen, causa y condicionalidad de hipótesis alternativa}

Apenas mencionado en la Nueva gramática de la lengua española (2009, $\$ 47.5 .2 b$, pp. 914-915), el esquema de preposición + infinitivo aparece solo con $a$ y de (este último "de

\footnotetext{
${ }^{3}$ Ejemplos citados en Marcovecchio y Pacagnini (2013: 103-105).
} 
gran vitalidad en la lengua actual") en prótasis condicionales antepuestas, que no alternan con grupos nominales ni con pronombres.

En Krnetić (2012), se insiste en que el infinitivo con de, cuando se interpreta como condicional, destaca la idea de causalidad, con un significado próximo al de la prótasis con en caso de (que), locución conjuntiva de sentido hipotético, de acuerdo con lo que proponen Hernanz (1999) y Montolío (1999). Precisamente Montolío (1999: 3676) sostiene que la locución si acaso aúna el significado hipotético de $s i$ con el de casualidad de acaso, y de allí refuerza la noción de 'condición azarosa' y la de 'duda', equivalente a si por casualidad o a quizás.

En esta línea, Krnetić evalúa que el empleo es anómalo en contextos que no manifiestan incertidumbre, de lo que también deriva que la prótasis condicional con de no admita ser usada en empleos genéricos, dado que en ellos se afirma un contenido como una verdad universal. Sin embargo, si volvemos sobre el ejemplo: ${ }^{\star}$ [De ser tú mi padre,] harás lo que te pido (Krnetić, 2012: 107), que considera agramatical en tanto no se expresa incerteza en la prótasis, podemos advertir que si se aplicara, por caso, a una situación en que se estuviera esperando la confirmación, con una prueba de $A D N$, del origen biológico de una persona, el condicionante con de se torna enteramente aceptable, justamente porque se vuelve accesible una interpretación según la cual la paternidad está en tela de juicio: es posible que tú seas mi padre o que no lo seas.

Por nuestra parte, insistimos en el hecho de que el vínculo causal deviene del de 'origen' en la localización en el es- 
pacio y en el tiempo. Asimismo, corroboramos que muchos de los circunstanciales de causa articulados con de tienen un comportamiento cercano al de un régimen verbal (Marcovecchio y Kaller, 2013). De ahí que Montolío (1999: 3690) compare Te habrían acusado, de haberlo dicho (='te habrían acusado si lo hubieras dicho') y Te habrían acusado de haberlo dicho (= 'te habrían acusado de ello'), con el propósito de mostrar qué requisitos deben confluir en la estructura de infinitivo preposicional con de para conducir a una interpretación condicional.

En cuanto al grado de fijación de la estructura del infinitivo preposicional, notamos que existe un proceso de gramaticalización consolidado. De hecho, en la prótasis con de, la estructura de infinitivo no es conmutable por una cláusula con verbo finito, acepta pasivizarse (3), por ejemplo, y admite su empleo tanto en períodos condicionales reales (3) y potenciales (4), en que es parafraseable por si más predicado en presente del modo indicativo o pretérito imperfecto del modo subjuntivo, respectivamente, como también en contrafácticos (5), con infinitivo compuesto equivalente a verbo finito en pretérito pluscuamperfecto del modo subjuntivo:

(3) De ser encontrado culpable, Mangeri recibirá la pena de prisión perpetua (La Nación, Buenos Aires, 22.01.2014 | Seguridad). [Consulta realizada en www.lanacion.com.ar_el 01/03/2014]

(4) ...lo que implica, en el peor de los casos, una sanción a posteriori, nunca de manera preventiva, ya que de hacerlo se incurriría en censura previa (La Nación, Buenos Aires, 22.12.2013 
| Opinión). [Consulta realizada en www.lanacion.com.ar_el 28/12/2013]

(5) "De haber habido un protocolo las personas podrían haber salido de sus viviendas y salvar sus vidas" (La Nación, Buenos Aires, 27.01.2014 | Sociedad). [Consulta realizada en www.lanacion. com.ar_el 01/03/2014]

Ahora bien, lo que revelan los ejemplos anteriores es que lo peculiar de la lectura del infinitivo introducido por de como condicional es que, sumado al valor causal remanente, pueda explicitar uno de los dos polos de una oposición semántica de complementariedad (como ocurre en las cláusulas de lectura deóntica con verbos de 'comunicación'). Para que esta interpretación quede disponible es necesario que en el contexto particular pueda activarse. En (3), la propia naturaleza de un proceso judicial lleva a que el imputado sea encontrado culpable o no y esto motiva la posible prisión perpetua. Al igual que en (4): que la sanción fuera preventiva o a posteriori, desencadena la posibilidad de incurrir en censura previa. En (5), por el carácter contrafáctico del infinitivo compuesto, entendemos que no ha habido un protocolo; no obstante, permanece latente la alternativa complementaria: que hubiera habido un protocolo y que, por lo tanto, las personas hubieran podido salir de sus viviendas y salvar sus vidas.

Efectivamente, los datos permiten entrever la recurrencia de estas prótasis de infinitivo a continuación de enunciados cuyos contenidos dejan abiertas dos alternativas hipotéticas complementarias (en (6), el postularse o no como 
candidato para el gobierno; en (7), el salir o no salir), de las cuales el infinitivo preposicional explicita una.

Dada la continuidad discursiva, la interpretación condicional de $d e+$ infinitivo se ve favorecida por contenidos previos relacionados con el 'deseo' o el 'pedido' que inciden sobre la lectura de alternativas complementarias. Cuando esta interpretación no es accesible, se desbarata el lazo condicional:

(6) ...de manera tímida, esta vez Randazzo avanzó un paso más en su deseo de postularse y confió que de ser candidato, lo será dentro del proyecto político que encarna la jefa del Estado ( $\mathrm{La} \mathrm{Na-}$ ción, Buenos Aires, 15.01.2014 | Política). [Consulta realizada en www.lanacion.com.ar_el 28/02/2014]

(7) “Estamos listos", señaló ayer el dirigente demócrata, y pidió a los residentes no salir y, de hacerlo, utilizar el transporte público, aunque mencionó posibles retrasos en el servicio (La Nación, Buenos Aires, 03.01.2014 | El Mundo). [Consulta realizada en www.lanacion.com.ar el 01/02/2014]

Ya Krnetić (2012) ha advertido que de ser así repite implícitamente el contenido de lo previamente expuesto, convirtiéndolo en una hipótesis. De este modo, la información del discurso anterior llega a ser una situación imaginaria que se acepta como una condición de la apódosis que sigue (8):

(8) ...Aviación Civil (ANAC) informaron que la tripulación del DL101 nunca avisó que el avión tenía algún problema porque, $d e$ ser así, se hubiese desplegado el plan de aterrizaje de emergencia 
(La Nación, 22.01.2014 | Buenos Aires). [Consulta realizada en www.lanacion.com.ar_el 01/03/2014]

Por esta razón, de puede ser parafraseado por en caso de (9)-(10), locución que convencionaliza el significado dubitativo de la oposición complementaria:

(9) En caso de ser un monto superior, también se aplica el mismo tributo... (La Nación, Buenos Aires, 22.01.2014 | Tecnología). [Consulta realizada en www.lanacion.com.ar_el 01/02/2014]

(10) ...cartera porteña dijeron ayer a LA NACION que "el control del transporte público corresponde a la CNRT, aunque en caso de haber un control de tránsito y uno de esos vehículos esté en falta, corresponde que se retenga la licencia de conducir del chofer... (La Nación, 25.01.2014 | Buenos Aires). [Consulta realizada en www.lanacion.com.ar_el 01/03/2014]

En este sentido, tal como ocurre con las llamadas procondicionales (Pacagnini, 2012) con para, también la construcción con de puede insertarse en un período condicional en que la apódosis revela el contenido producto de la inferencia deductiva realizada por el locutor (11) a partir de lo enunciado en la prótasis. Esto es, debe haber ocurrido en el trayecto Buenos Aires-Montevideo es una aserción de carácter evidencial. Nótese, no obstante, que la lectura condicional del infinitivo preposicional se relaciona con la secuencia anterior, no hubo aviso de emergencia, con la que establece una oposición complementaria (de haber habido un desperfecto): 
(11) Desde el organismo [ANAC] confirmaron que el piloto tomó la decisión de aterrizar en el aeropuerto de Montevideo y "no informó en ese momento ninguna falla". "Se supone que si tiene un ala rota debe avisar; si hubiera habido alguna falla nos habríamos enterado al instante para desplegar el sistema de emergencia", precisaron. Desde la ANAC enfatizaron que "no hubo aviso de emergencia" y consideraron que de haber habido un desperfecto debe haber "ocurrido en el trayecto Buenos AiresMontevideo" (La Nación, 22.01.2014 | Buenos Aires). [Consulta realizada en www.lanacion.com.ar_el 01/02/2014]

Desde el punto de vista temporal, el infinitivo compuesto expresa anterioridad con respecto al presente de la enunciación; por esta razón, el contenido de la predicación puede interpretarse como la causa, contraria a los hechos, que desencadena la inferencia deductiva del locutor: el desperfecto tiene que haber ocurrido no en el recorrido previo: AtlantaBuenos Aires, sino en el siguiente: Buenos Aires-Montevideo, y esta deducción se deriva, necesariamente, del hecho constatado de que no haya habido aviso de emergencia anterior.

En lo que concierne a las condicionales de la enunciación, se insiste en que la incertidumbre que manifiesta $<d e+$ infinitivo > no suele ser compatible con ellas, excepto en los casos de "condición indirecta procesural" (Montolío, 1999: $\S \S 57.5 .1 .1, \S \S 57.5 .2)$, como en (12). En realidad, lo que comprueba (12) es que como el locutor ofrece la posibilidad de que le escriban para que él pueda brindar información, la prótasis con de es compatible con la interpretación de contingencia 'en el caso de que se necesiten más datos'. De manera similar, si bien en (13) no se emplea el modo sub- 
juntivo con valor de imperativo en la apódosis, la perífrasis verbal se puede borrarlos expresa modalidad deóntica, por lo que activa la interpretación de oposición complementaria en el condicionante:

(12) De necesitar más datos, escríbanme a mi mail, y con gusto les acerco información. Pertenezco a la Iglesia Evangélica Bautista, de la calle 24 de Octubre 1059 (Ituzaingó) y formamos parte del grupo de colaboradores de este evento (http://www.ituza.com. ar/cartas.htm). [Consulta realizada el 10/05/2014]

(13) Se puede ver qué aplicaciones y archivos están ocupando el almacenamiento interno del equipo, y borrarlos, de ser necesario (La Nación, Buenos Aires, 27.01.2014 | Tecnología). [Consulta realizada en www.lanacion.com.ar_el 01/03/2014]

En cambio, presenta restricciones el esquema $<d e+$ infinitivo > con otro tipo de condicionales de la enunciación, como las que caracterizan al locutor como dicente honesto o las que aluden a su nivel de conocimiento de los hechos que enuncia (Kovacci, 1992). En el primer caso, una condicional de garantía de franqueza en el decir, del tipo si soy sincero, no admite cuestionamiento alguno: expone un axioma constitutivo del intercambio comunicativo por el cual ningún locutor podría presentarse como deshonesto. En el segundo caso, al indicar el grado de conocimiento sobre el que se asienta la aserción del locutor, como si la memoria no me falla / si no me equivoco, se atenúa el compromiso epistémico del hablante en relación con lo que afirma en la apódosis, pero no admite el reverso (que la memoria me fa- 
lle / que me equivoque) porque no podría servir de fundamento para enunciar algo. Se trata de formas relativamente cristalizadas (Marcovecchio, 2001 y 2012) que introducen comentarios, que no pueden ser reversibles, sobre dos esferas del acto comunicativo.

\section{Para + infinitivo: destino, causa final y condicionalidad de suficiencia y de propósito}

\section{1. 'Destino' y 'causa final'}

La noción de 'finalidad' está muy emparentada con la de 'destino' o 'meta' (Lo propusieron para una beca), al extremo de que en algunos casos se torna muy dificultoso discriminar una de otra. De hecho, la acepción 'final' de para se deriva, por extensión semántica, del sentido espacial de la preposición latina pro, que significa "movimiento hacia adelante" (Riiho, 1979: 187-189).

La finalidad concebida como 'causa final' (Pacagnini, 2012) se entiende como el fin, propósito u objetivo con el que se realiza una acción, que supone necesariamente una intencionalidad (lo cual la diferencia de conceptos como 'destino', 'destinatario', 'concesión', 'suficiencia', etc., que no son propiamente intencionales). Es la construcción <para + infinitivo $>$ la que se ha consolidado como expresión lingüística de esta causa "virtual e intencional" en estructuras del tipo de Estudio para aprobar, denominadas "finales puras", las cuales poseen un sujeto prototípicamente [+ animado] y en las que la construcción con para admite una paráfra- 
sis causal con porque más un verbo de 'volición' (Estudio porque quiero aprobar). Así, este tipo de construcciones suponen una relación de causa-efecto en que el efecto es posterior (propósito no realizado o 'virtual'); ese 'propósito, a la vez, se interpreta como la causa, el motivo o el fundamento que induce a la intervención de un agente (Pacagnini, 2012: 67). Sin embargo, no es necesario que dicho 'agente intencional' siempre esté explícito: muchas veces es suficiente con que este pueda presuponerse del conjunto de lo enunciado.

Por ello, puede haber pequeños desvíos: por ejemplo, en (14), "el rayo" no posee el carácter volitivo propio del agente humano, pero sí se interpreta como un causante, en tanto fuerza:

(14) ¿Qué pasa cuando hay tormentas eléctricas? Lo primero que hay que saber es que el rayo para tener un efecto destructivo tiene que encontrar el otro signo $y$, cuando lo encuentra en su camino, no debería interponerse resistencia alguna, porque el efecto sería demoledor (La Nación, Buenos Aires, 23.01.2014 | Opinión). [Consulta realizada en www.lanacion.com.ar_el 01/02/2014]

También es posible que el vínculo de 'causa final' se mantenga, pero dado que forma parte de un período en que el constituyente principal describe un contenido contrafáctico, en la finalidad también se anula el valor de realización eventual, como en (15), puesto que al no haber participado en la fiesta y no haber sido espectador tampoco logró disfrutar del club, de la ciudad: 
(15) Haber participado en esta fiesta es un gran recuerdo, me hubiera gustado ser espectador para haber disfrutado del club, de la ciudad. Es un orgullo tener una afición así (Canchallena, La Nación, Buenos Aires, 01.02.2012 | Fútbol). [Consulta realizada en www. canchallena.lanacion.com.ar_el 15/12/2013]

\subsection{Construcciones procondicionales con para}

\subsubsection{Procondicionales deónticas}

En Marcovecchio y Pacagnini (2013 y en prensa), hemos analizado el vínculo estrecho que se establece entre las construcciones de 'causa final' (o finales prototípicas) y aquellas procondicionales de valor deóntico encabezadas por para. $\mathrm{Al}$ igual que en las "auténticas" finales, la cláusula con para de interpretación deóntica expresa un efecto buscado, se orienta prospectivamente y resulta incompatible con el infinitivo compuesto, todo lo cual confluye en la expresión de un contenido de realización 'eventual. Sin embargo, en las procondicionales (a diferencia de lo que ocurre en las estrictamente finales), también el otro segmento oracional indica 'eventualidad', en tanto se halla sujeto a la irrealidad de la modalidad deóntica que le otorga el locutor a su enunciado (16)-(19):

(16) "Les explicamos [a los manifestantes] que para tener esa reunión, debería cesar el corte. No íbamos a ceder ante una extorsión [...]" (La Nación, 07.01.2014 | Buenos Aires). [Consulta realizada en www.lanacion.com.ar_el 01/03/2014] 
(17) Según el ex director ejecutivo de la Fundación ExportAr, para tener éxito "se debe trabajar rápidamente en la mejora en la reputación argentina en el exterior [...]" (La Nación, Buenos Aires, 14.01.2014 | Comercio exterior). [Consulta realizada en www. lanacion.com.ar_el 02/03/2014]

(18) Romeo entiende que para ser manager hay que dominar otras habilidades que no son... (Canchallena, La Nación, Buenos Aires, 22.01.2014 | Fútbol). [Consulta realizada en www.canchallena.lanacion.com.ar_el 01/03/2014]

(19) "Para ser movidas desde su lugar original hasta el pasto se necesita asegurarlas con bandas y sogas especiales..." (La Nación, 17.01.2014 | Buenos Aires). [Consulta realizada en www.lanacion.com.ar_el 01/03/2014]

El carácter prospectivo de estas cláusulas con para se constituye en un rasgo determinante para la lectura deóntica (y la consiguiente interpretación 'eventual' del condicionado), como puede observarse al realizarse una paráfrasis con $s i$ + verbo volitivo (en el caso de (19a), se requieren algunos otros ajustes debido a que la estructura es pasiva sin agente explícito):

(16a) Si se quiere tener esa reunión, debería cesar el corte [...]

(17a) Si se quiere tener éxito, se debe trabajar rápidamente en la mejora en la reputación argentina en el exterior [...]

(18a) Si se quiere ser manager, hay que dominar otras habilidades [...] 
(19a) Si se las quiere mover desde su lugar original hasta el pasto, se necesita asegurarlas $[\ldots]$

Por esto, de alguna manera, se "invierte" la relación condicional típica de suficiencia: si cesa el corte, podrán tener esa reunión, en (16); si se trabaja rápidamente, se tendrá éxito, en (17); si se dominan otras habilidades, se puede ser manager, en (18); o si se necesita asegurarlas, se las puede mover desde su lugar original hasta el pasto, en (19).

\subsubsection{Procondicionales epistémicas}

En estas procondicionales de valor epistémico se produce un desplazamiento desde la acción prospectiva intencional propia de la 'finalidad' (Pacagnini, 2012): el contenido no se presenta como un objetivo buscado en relación con lo manifestado por la oración principal, sino como un propósito del desencadenamiento de una inferencia causal inductiva, que realiza el locutor, incluida en el segmento matriz. En estas "falsas finales" (Galán Rodríguez, 2007) epistémicas, el infinitivo compuesto en la cláusula con para se asocia a la interpretación evidencial de la apódosis, cuyo contenido se expone como resultado de un acceso indirecto a la información por parte del locutor: en (20), el periodista deduce de que Ferrer llegara hasta la final de Wimbledon que buenas razones tenía para eso; o en (21), infiere de que Galarza dejara sus estudios avanzados de Medicina y los afectos que demuestra una gran madurez:

(20) Porque no todos los días se gana un partido como el que Del Potro le ganó al bueno de Ferrer por 6-2, 6-4 y 7-6 (5), en 2h16m. 
No es algo de rutina estar entre los cuatro mejores del torneo más famoso del mundo, no. [...] Delpo se la jugó. Y jugó un partidazo. Le tocó sufrirlo a Ferrer, que también tenía sus inconvenientes - un esguince en el tobillo izquierdo, por el que se infiltró para jugar-, pero no por eso era un adversario menos peligroso; a fin de cuentas, sus buenas razones tenía el alicantino para haber llegado hasta aquí también (La Nación, Buenos Aires, 04.07.2013 | Deportiva). [Consulta realizada en www.lanacion. com.ar_el 21/12/2013]

(21) Pese a ser un argentino recién llegado —arribó en agosto-, los primeros contactos con sus nuevos compañeros fueron amenos gracias a esta sencillez que Galarza mencionaba [...]. El entusiasmo por el rugby también lo hizo sentirse acogido en Irlanda [...]. La adaptación no resultó traumática. Demuestra una fuerte madurez para haber dejado el estudio y los afectos a los 22 años (cumplió 23 durante esta gira) (La Nación, Buenos Aires, 23.11.2010 | Deportiva). [Consulta realizada en www.lanacion. com.ar_el 15/02/2014]

Es decir, las posibles paráfrasis dejan en evidencia que estas "condicionales epistémicas" se caracterizan por situar la implicación condicional en el plano de la enunciación, habilitando una inferencia de tipo causal (Kovacci, 1992):

(20a) Si Ferrer ha sido capaz de llegar hasta la final de Wimbledon (pese a los inconvenientes), es porque sus buenas razones tenía.

(21a) Si Galarza ha sido capaz de dejar el estudio y sus afectos a los 22 años, es porque demuestra [tener] una fuerte madurez. 
Ciertamente, se genera este deslizamiento semántico entre la 'finalidad' y la 'condición' porque existe un vínculo causal implícito entre prótasis y apódosis, en el nivel de la enunciación. En el contenido de la cláusula con para se traslucen dos encadenamientos temporales: el de los hechos, por un lado, que se refleja en que la prótasis tienda a ubicarse en segundo lugar; y el de la enunciación, por el otro. Este último pertenece al proceso inductivo: el locutor sabe que Ferrer llegó hasta la final de Wimbledon o que Galarza sacrificó sus estudios y la cercanía de sus afectos; y de estos hechos, cuya verdad presupone, infiere, con posterioridad, un posible motivo que los justifique. El que queden involucrados dos encadenamientos temporales es lo que provoca que se admitan paráfrasis tanto causales con porque (cfr. (20a) y (21a)) como consecutivas con entonces (cfr. (20b) y (21b)):

(20b) Si Ferrer llegó hasta la final de Wimbledon (pese a los inconvenientes), entonces sus buenas razones tenía.

(21b) Si Galarza dejó sus estudios y sus afectos a los 22 años, entonces demuestra [tener] una fuerte madurez.

\subsubsection{Procondicionales de la enunciación}

Se trata de fórmulas aptas para la calificación del locutor como dicente y para la organización del discurso (Marcovecchio, 2001 y 2012), en que la presencia del infinitivo se enlaza con la correferencialidad implícita entre el sujeto de la predicación y el que enuncia o los que participan del intercambio comunicativo. Estas construcciones 'procondicio- 
nales' (22)-(25), que expresan la 'causa final' o el propósito del acto de habla, aceptan ser parafraseadas - aunque con limitaciones, debido a una marcada cristalización gramatical- por prótasis condicionales modificadoras de la enunciación que destaquen el propósito del locutor (22a)-(25a), incluso como advertencias hacia el alocutario (24)-(25); por este motivo, para es el nexo predominante en el empleo de estos infinitivos preposicionales, aunque también es posible por en las cláusulas que explicitan el ordenamiento y la organización entre segmentos discursivos, en particular, en el caso de los marcadores de concreción del tipo para / por poner un ejemplo:

(22) "Para ser sincero, ni siquiera yo lo sé", dijo Murray (Canchallena, La Nación, Buenos Aires, 21.01.2014 | 11:30 | Tenis). [Consulta realizada en www.lanacion.com.ar_el 01/03/2014]

(22a) Si he de ser sincero, ni siquiera yo lo sé.

(23) Nacido en 1954, en una familia de viñateros de la Champagne - para ser preciso, en la coqueta localidad de Vertus-, con seis generaciones a la espalda haciendo la misma tarea, su camino lucía... (Brando, Buenos Aires, 16.01.2014). [Consulta realizada en http://www.conexionbrando.com/_el 02/03/2014]

(23a) [...] si hablamos con precisión, en la coqueta localidad de Vertus $[\ldots]$.

(24) Para tener términos de comparación, los inmuebles frente al mar en los barrios más cotizados de Río de Janeiro, como Ipanema y 
Leblon, promedian alrededor de 30.000 reales (12.600 dólares) el m2 (La Nación, Buenos Aires, 25.01.2014 | Propiedades). [Consulta realizada en www.lanacion.com.ar_el 03/03/2014]

(24a) Si queremos tener términos de comparación, los inmuebles frente al mar $[\ldots]$.

(25) Para tener una idea, en la playa, con la posibilidad de mojar los pies en la orilla del mar, una cerveza cuesta 4 reales [...] ( $\mathrm{La} \mathrm{Na-}$ ción, Buenos Aires, 12.01.2014 | Sociedad). [Consulta realizada en www.lanacion.com.ar_el 01/03/2014]

(25a) Si queremos tener una idea, en la playa [...].

\section{Conclusiones}

De acuerdo con lo hasta aquí considerado, podemos corroborar que de y para no resultan intercambiables en las prótasis condicionales de infinitivo, ya que al retener ambas preposiciones parte de su caudal de significado primario, más allá de ingresar en un proceso de gramaticalización, proyectan sobre la cláusula un determinado potencial semántico.

De ahí que con de predomine la interpretación condicional que explicita uno de los dos polos de una oposición complementaria, algo que se imprime sobre el valor causal derivado del significado de localización de 'origen'. El infinitivo preposicional conserva el significado de 'anterioridad' con respecto al contenido de la apódosis y requiere que el 
contexto situacional o lingüístico active la lectura de realización hipotética (o contrafáctica), equivalente a lo que se expresa con la locución en caso de (que). Si no, no puede ser un formato válido para la manifestación de la condicionalidad, ni del enunciado ni de la enunciación.

En cambio, en la prótasis con para subyace el contenido de 'causa final' $y$, en consecuencia, el carácter prospectivo del infinitivo con respecto a la apódosis incide sobre las diferentes lecturas condicionales posibles: de efecto buscado (a partir de un lazo de suficiencia entre los miembros del período), de efecto logrado (lo que desencadena una causa inferida por el locutor) o de propósito del decir.

Ambas preposiciones comparten la posibilidad de expresar un vínculo causal entre dos constituyentes, por lo que es posible la reinterpretación de las cláusulas en que se insertan como prótasis condicionales. Pero difieren en la perspectiva (de origen o de meta), como ocurre en los empleos básicos de la expresión de la localización.

\section{Bibliografía}

Albano, H. (1985), "La construcción condicional en español 'con + infinitivo'", Revista de la Facultad de Filosofía y Letras de la Pontificia Universidad Católica Argentina Santa María de los Buenos Aires, XIV, pp. 83-89.

GAlÁn Rodríguez, C. (2007), La renovación de nexos: las falsas finales, Alicante, Biblioteca Virtual Miguel de Cervantes. 
Hernanz Carbó, M. Ll. (1999), "El infinitivo”, en I. Bosque y V. Demonte (coords.), Gramática descriptiva de la lengua española, vol. 2, Madrid, Espasa Calpe, pp. 2197-2356.

Kovacci, O. (1992), El comentario gramatical, II, Madrid, Arco Libros.

KRnetić, D. (2012), La construcción española [DE + infinitivo] con valor condicional. Un análisis contrastivo con las condicionales inversas del inglés (tesis doctoral), Barcelona, Universidad Autónoma de Barcelona, disponible en www.ub.edu/edap/

Marcovecchio, A. (2001), "Contenidos nocionales de las construcciones adverbiales de modalidad y relaciones con los adverbios 'de oración'”, Español Actual, 76, pp. 5-23.

- (2012), "De las circunstancias de los eventos a las de la emisión: gramaticalización y evidencialidad”, en E. Vucheva (coord.), El español: territorio de encuentros, Sofía, Universidad “San Clemente de Ojrid”, pp. 65-75. Marcovecchio, A., H. Albano y A. Kaller (2014), “'De + infinitivo': entre la modalidad deóntica y la condicionalidad", Signo y Seña, 25, pp. 215-229.

Marcovecchio, A. y A. Kaller (2013), " $<A(l) / d e+$ infinitivo> como cláusulas adverbiales", en A. M. Marcovecchio A. Ghio y M. Cuñarro (eds.), En torno a la morfosintaxis del español. Volumen temático de la Sociedad Argentina de Lingüistica (EBOOK), Mendoza, Facultad de Filosofía y Letras, Universidad de Cuyo / Sociedad Argentina de Lingüística, pp. 77-88. Disponible en http://ffyl.uncu.edu.ar/spip.php?article3654. 
Marcovecchio, A. y A. Pacagnini (2013), "Cuantificación e (in)suficiencia argumentativa: construcciones con para de contraexpectativa", CLAC, 55, pp. 95-110, disponible en http://www.ucm.es/info/circulo/no55/ marcovecchio.pdf

Marcovecchio, A. y A. Pacagnini (en prensa), "Para + infinitivo y la interpretación procondicional", en Actas del XVIII Congreso Internacional de Hispanistas, Buenos Aires, 15-20 de julio de 2013.

Montolío, E. (1999), "Las construcciones condicionales", en I. Bosque y V. Demonte (dirs.), Gramática descriptiva de la lengua española, vol. 3, Madrid, Espasa Calpe, pp. 3643-3738.

- (2000), "On affirmative and negative complex conditional connectives", en Couper-Kuhlen y Kortmann, Bernd (eds.), Cause, condition, concession, contrast (Cognitive and discourse perspectives), Berlín, Mouton de Gruyter, pp. 143-171.

PACAgnini, A. (2012), La expresión lingüística de la 'causa final. Su incidencia en la adquisición del español como lengua extranjera (tesis doctoral) (inédita), Buenos Aires, Universidad de Buenos Aires.

Riıho, T. (1979), Por y para. Estudios sobre los orígenes y la evolución de una oposición prepositiva iberorrománica, Helsinki, Helsingfors.

Real Academia Española y Asociación de Academias DE la Lengua Española (2009), Nueva gramática de la lengua española, Madrid, Espasa Calpe.

Rodríguez RAmalle, T. M. (2008), Las formas no personales del verbo, Madrid, Arco Libros. 
VANDerschueren, C. (2012), Infinitivo y sujeto en portugués y español. Un estudio empírico de los infinitivos adverbiales con sujeto explícito (tesis doctoral), Gante, Universidad de Gante, disponible en www.atilf.fr/cilpr 2013/.../49e359b3069bb5d8037ca032270633c3.pdf. 
